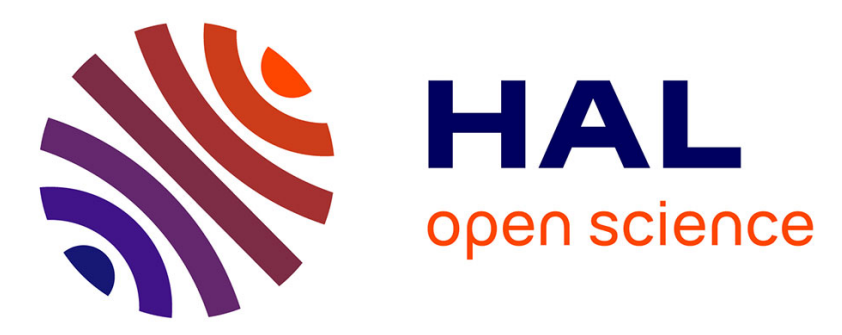

\title{
Response Enhancement of WO3 Gas Sensors by Metallic Nanograins
}

\author{
M. Othman, D Lollman, Khalifa Aguir, W Belkacem, N Mliki, Philippe \\ Menini
}

\section{- To cite this version:}

M. Othman, D Lollman, Khalifa Aguir, W Belkacem, N Mliki, et al.. Response Enhancement of WO3 Gas Sensors by Metallic Nanograins. IEEE Sensors 2013, Nov 2013, Baltimore, MD, United States. 10.1109/ICSENS.2013.6688193 . hal-02072195

\section{HAL Id: hal-02072195 \\ https://hal.laas.fr/hal-02072195}

Submitted on 19 Mar 2019

HAL is a multi-disciplinary open access archive for the deposit and dissemination of scientific research documents, whether they are published or not. The documents may come from teaching and research institutions in France or abroad, or from public or private research centers.
L'archive ouverte pluridisciplinaire HAL, est destinée au dépôt et à la diffusion de documents scientifiques de niveau recherche, publiés ou non, émanant des établissements d'enseignement et de recherche français ou étrangers, des laboratoires publics ou privés. 


\section{Response Enhancement of $\mathrm{WO}_{3}$ Gas Sensors by Metallic Nanograins}

M. Othman, D. Lollman, K. Aguir

1IM2NP/CNRS, Aix-Marseille Université, , 13397, Marseille cedex 20, France.

P.Ménini

LAAS-CNRS, 7 Av. du Colonel Roche, 31077 Toulouse, France. khalifa.aguir@im2np.fr

\begin{abstract}
In the present work, we have studied the effect of metal nanoparticles on the enhancement of the sensor response. These nanoparticles were deposited on the surface of $\mathrm{WO}_{3}$ sensors. In a second step, we have focused on a theoretical study to simulate the response of the sensor to determine influenced parameters related to response time.
\end{abstract}

\section{INTRODUCTION (HEADING 1)}

Metal oxide $\mathrm{WO}_{3}$ exhibit anionic vacancies that give it ntype semiconductor character. The sensing principle is based on the variation of the resistance (or conductance) in the presence of oxidizing or reducing gases. The change of electrical properties of the metal-oxide semiconductor is directly related to the adsorption of gas molecules which can generate surfaces states and then gives rise to am electronic charges transfer between the conduction band and these states.

It is therefore of great interest to study and implement gas sensors using tungsten trioxide as sensitive layers for the detection of gaseous species. This is particularly true at the level of sensitivity and selectivity which are two of the main challenges to the for developers of metal-oxide gas sensors and until now limit the performance of these devices. A possible approach for enhancing the sensitive and selective properties of gas sensors are quoted the use is speculated by additive catalysts based on noble metals ( $\mathrm{Pd}, \mathrm{Au}, \mathrm{Ag}$...) [1]. This surface modification which leads to a new chemical reactivity by establishing chemical bonds of metal-metal oxides has been implemented to improve the response and the sensitivity of tungsten trioxide gas sensors.

The aim of this work is to analyze the influence of the metal additive on the gas sensor performance. In order to achieve this objective, three different metallic nanoparticles (gold, silver and cobalt) are used to change the surface properties of the tungsten oxide sensors. The catalytic effect on the sensor characteristic is usually associated to a distribution of the additive nanoparticles through the whole sensing material surface.

\section{SENSORS DESIGN}

The sensors are formed by a micro-hotplate platform and a $\mathrm{WO}_{3}$ sensing layer. The heater consists of a silicon substrate

\author{
M. Othman, W. Belkacem, N. Mliki \\ LMOP, Faculté des Sciences, Université Tunis El Manar, Tunis, \\ Tunisia.
}

with a $\mathrm{SiO}_{2}-\mathrm{SiN}_{\mathrm{x}}$ bi-layer membrane, on which a Pt heater is placed. Above the heater, an insulating layer is deposited followed by interdigitated electrodes and then a thin layer of $\mathrm{WO}_{3}$. (Fig. 1).

The $\mathrm{WO}_{3}$ sensing thin film was prepared by reactive radio frequency (13.56 MHz) magnetron sputtering. The film is sputtered on the top of the interdigitated electrodes using a 99.9\% pure tungsten target in a reactive atmosphere under controlled oxygen-argon mixtures. After the deposition and a lift-off of the sensitive layer, the film was annealed at $400^{\circ} \mathrm{C}$ in air for 90 minutes in order to stabilize the chemical structure.

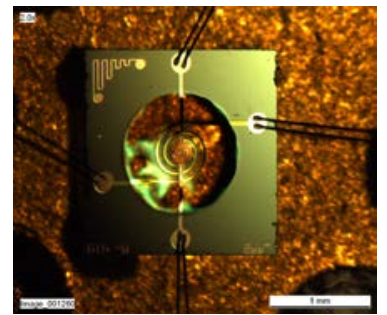

Fig. 1. $\mathrm{WO}_{3}$ gas sensor with the micro-hotplate

The sensors are introduced in a test chamber allowing investigating of resistance variation under different gas concentrations after exposure to dry air as reference gas. The typical operating temperature giving the highest sensitivity for these sensors is about $270^{\circ} \mathrm{C}$.

Ozone is generated by oxidizing oxygen molecules of a dry air exposed to a UV lamp. In the other hand, ethanol vapors were generated by blowing dry air through an ethanol /water mixture in thermostatic bath kept at $34{ }^{\circ} \mathrm{C}$. The resultant air will contain humidity and evaporated ethanol with a concentration in air that follows the Dubowski's formula.

\section{RESULTS AND DISCUSSION}

Among the important sensing characteristics in gas sensing are quoted gas response and response time. Gas response is defined as the ratio of the resistance of a sample on exposure to a test gas to the resistance in air for oxidizing gases, but as the reverse ratio when the resistance decreases in reducing gases. It can be written as. 


$$
\begin{array}{ll}
S=R_{\text {gas }} / R_{O} & \text { for oxidizing gases } \\
S=R_{0} / R_{\text {gas }} & \text { for reducing gases }
\end{array}
$$

where $R_{g a s}$ and $R_{0}$ are the resistances in the presence of test gas and in air, respectively. Response time is defined as the time needed for a sensor to attain $90 \%$ of maximum change in resistance upon exposure to a test gas.

\section{A. Gold nanoparticles}

The electrical resistance of pure and gold-modified $\mathrm{WO}_{3}$ thin films was measured as a function of time at $300^{\circ} \mathrm{C}$ ???? $270^{\circ} \mathrm{C}$ ???. Figure 2 shows the variation of logarithm of the film resistance under various ozone concentrations before and after gold deposition as a function of time. The gold nanoparticles were deposited onto the $\mathrm{WO}_{3}$ surface by vacuum evaporation with an equivalent thikness of $15 \AA$.

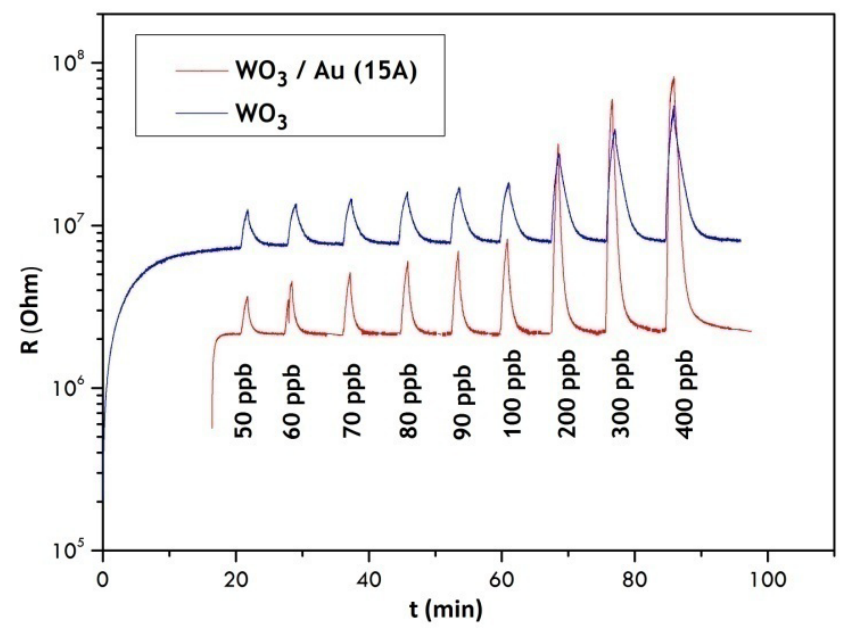

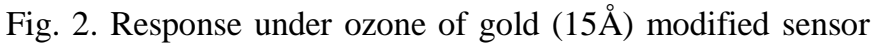
surface.

Figure 2 shows that there is a systematic decrease in baseline resistance from $8 \mathrm{M} \Omega$ to $2 \mathrm{M} \Omega$ after surface modification with gold nanoparticles. Stabilization time, which is about 20 minutes before gold deposition, was reduced also to 4 minutes.

Figure 3, representing the evolution of gas response mentioned above (for oxidizing gases) as a function of ozone concentration, demonstrates that the response of the $\mathrm{WO}_{3}$ material can be improved by incorporating gold nanoparticles onto the oxide film.
It is clear from figure 3 that for each tested concentration, the response has been enhanced. It should be noted here that the addition of the $15 \AA$ gold film resulted in an increase in sensor response by more than five orders of magnitude??? for 300 and $400 \mathrm{ppb}$ ozone concentration. Implementing gold nanoparticles can also reduce slightly the response time, from $25 \mathrm{~s}$ to $21 \mathrm{~s}$ for $60 \mathrm{ppb}$.

Fig. 3. Comparison between the sensor response before and after gold deposition versus ozone concentrations.

The increase in resistance under ozone is considered to arise from electron transfer from the $\mathrm{WO}_{3}$ film to the Au due the difference between electron affinity of tungsten trioxide (3.33-3.94 eV) [2] and the Au work function (5.1 eV) and can also be assigned to the good dispersion of gold nanograins on the $\mathrm{WO}_{3}$ surface (Fig.4)

Fig. 4. SEM micrograph showing surface morphology of gold nanoparticles dispersed on $\mathrm{WO}_{3}$ surface.

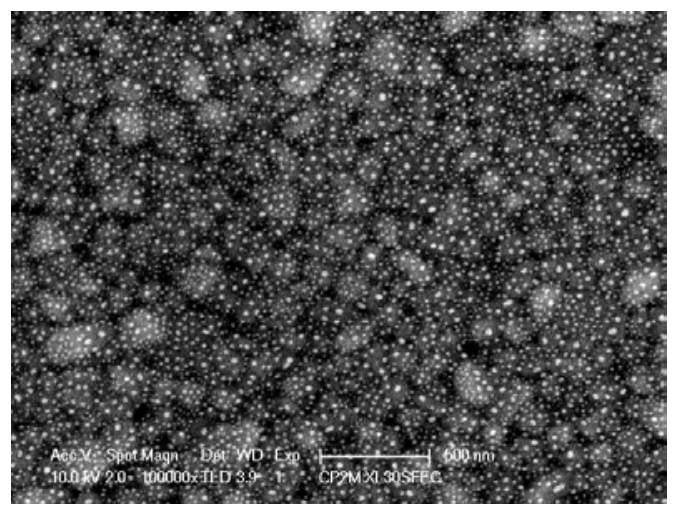

\section{B. Silver nanoparticles}

A thin silver film (15 $\AA$ ) was deposited onto the surface of another $\mathrm{WO}_{3}$ film to investigate the effect of the Ag nanograins on the performances of the sensor (response, time response, etc.).

Resistance measurements were carried out in the test chamber under ozone at $300^{\circ} \mathrm{C}$. Fig 5 shows the variation of resistance in the pure/Ag-modified $\mathrm{WO}_{3}$. The Ag behavior is the same compared to the gold case (i.e. in terms of response) but it is clear that both stabilization time and baseline resistance were increased.

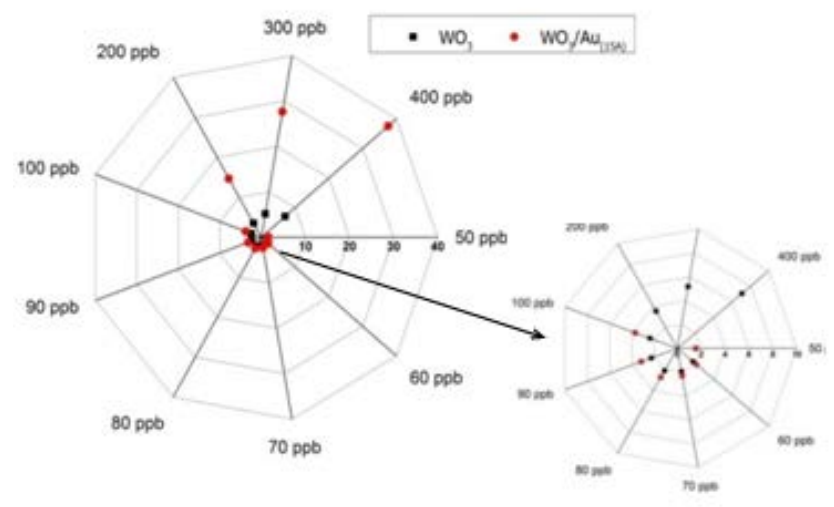




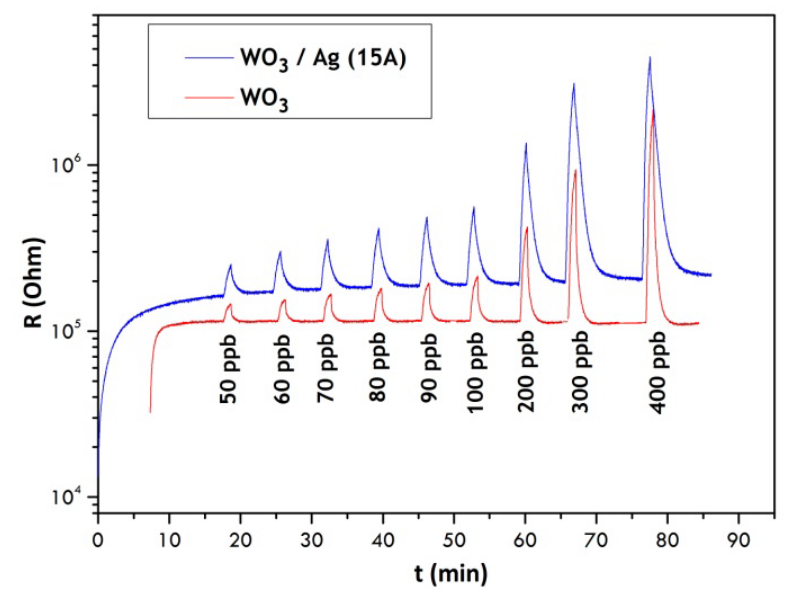

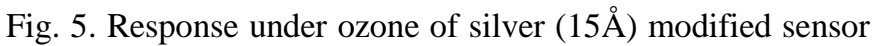
surface.

According to Fig 2, the increase in the baseline value is about 2 orders of magnitudes. Time stabilization changes from 10 minutes for the undoped layer to 17 minutes for Ag modified sensor.

To investigate response enhancement to ozone, the ratio $R_{g a s} / R_{o}$ was plotted as a function of ozone concentration. As shown in Fig 6. The presence of Ag nanograins in the surface of the $\mathrm{WO}_{3}$ improves, like the gold film case, the response to ozone.

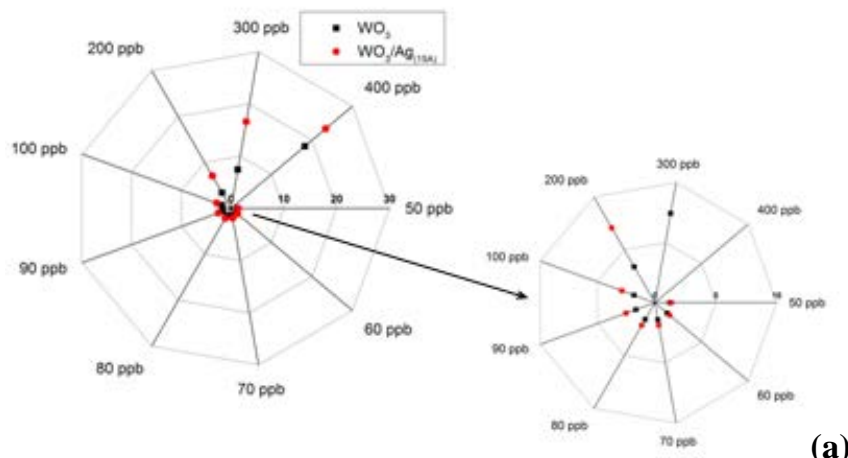

(a)

Fig. 6. Sensor response before (black square) and after gold deposition (red circles) to different ozone concentrations.

From Fig 6 shows that there is an increase in sensor response by more than two orders of magnitude for $300 \mathrm{ppb}$. The enhancement is small compared to the case of gold particles for the same ozone concentration; also the increase in both baseline resistance and time stabilization can be noticed to the oxidation of Ag. In fact, the transfer of electrons from $\mathrm{WO}_{3}$ to Ag during adsorption promotes the ionization of oxygen on the Ag. Another possible reason that can explain the modification mentioned above is the degradation of the $\mathrm{WO}_{3}$ sensitive layer as shown in Fig 7. Thus, the degradation of the film when the sensor is in operating mode can limit the density of $\mathrm{Ag}$ nanograins on the $\mathrm{WO}_{3}$ surface and then minimize the sensing mechanism.

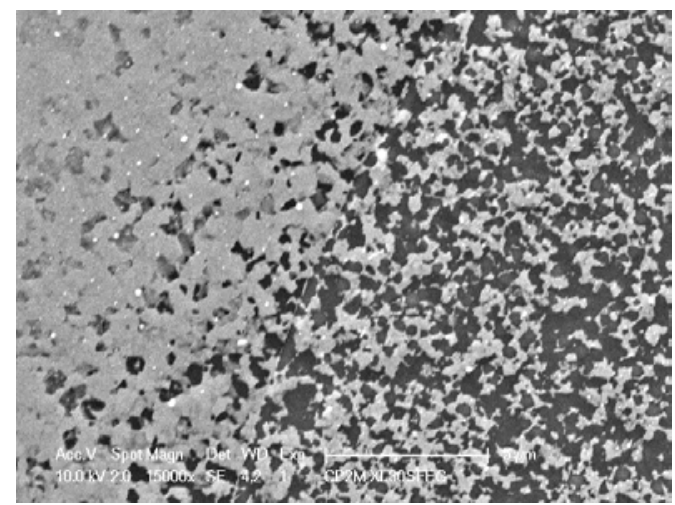

Fig. 7. SEM image showing surface morphology of silver nanoparticles (left) and degradation of the film (right).

\section{Cobalt nanoparticles}

In addition to gold and silver additives, a nanostructured cobalt film (30 $\AA$ ) was deposited onto the surface of another sensor. This shows $\mathrm{Co}-\mathrm{WO}_{3}$ behavior under reducing gas and also the particular effect of cobalt for oxidizing gas [3]. The testing gas in this case is ethanol with different concentrations. The resistance has been plotted as a function of time as shown in Fig. 8.
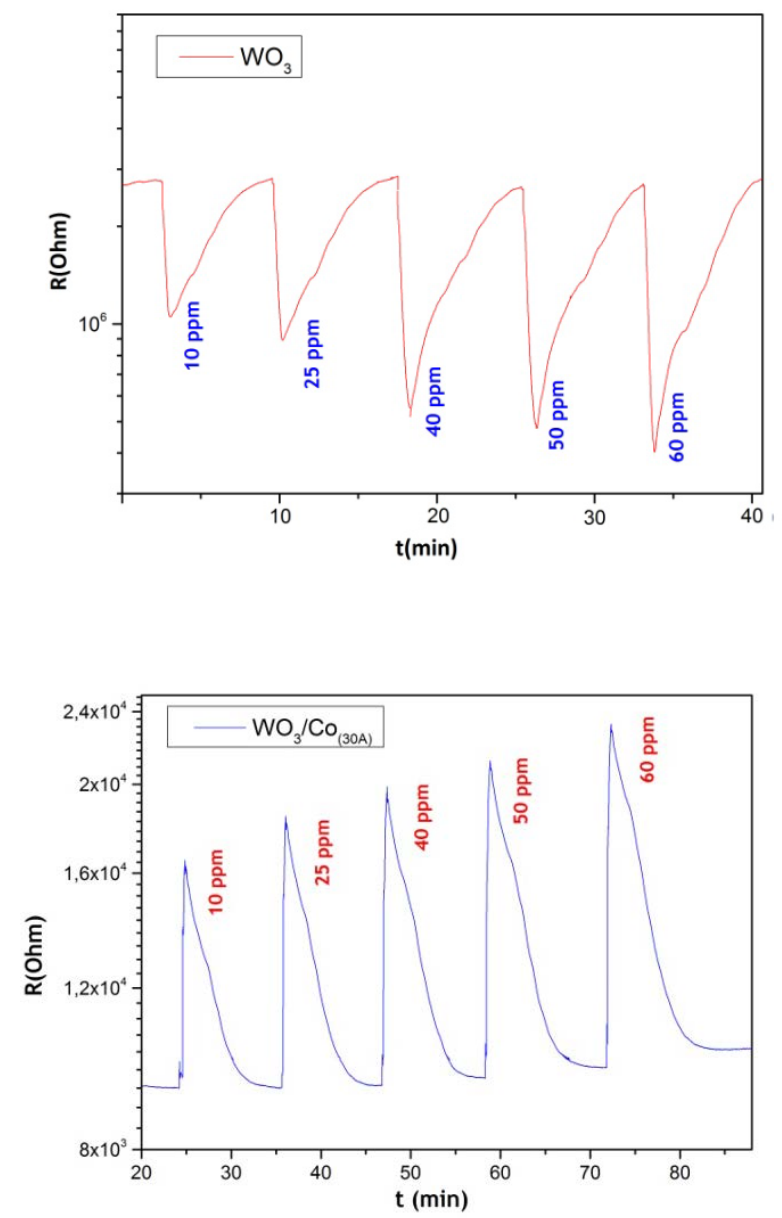

(b) 
Fig. 8. Response under ethanol of: a) unmodified $\mathrm{WO}_{3}$ and b) $\mathrm{Co} / \mathrm{WO}_{3}$ sensor surface.

Fig 8 demonstrates that the interaction of cobalt nanograins with $\mathrm{WO}_{3}$ surface modified in a radical way the response of the sensor. Thus, the $\mathrm{Co}-\mathrm{WO}_{3}$ sensor presents an increase in resistance. This behavior is normally the signature of oxidizing gases with n-type semiconductor or that for p-type semiconductor. It should be noted that similar effect was observed in the case of ozone which is an oxidizing gas [3].

A possible explanation of this behavior is related to the formation of cobalt oxide which is a p-type semiconductor that can dominate at the surface. This tends to prove that the conduction is essentially a surface conduction.

Fig. 4. SEM micrograph showing surface morphology of cobalt nanoparticles dispersed on $\mathrm{WO}_{3}$ surface.

[1] G. Eason, B. Noble, and I. N. Sneddon, "On certain integrals of Lipschitz-Hankel type involving products of Bessel functions," Phil. Trans. Roy. Soc. London, vol. A247, pp. 529-551, April 1955. (references)

[2] J. Clerk Maxwell, A Treatise on Electricity and Magnetism, 3rd ed., vol. 2. Oxford: Clarendon, 1892, pp.68-73.

[3] I. S. Jacobs and C. P. Bean, "Fine particles, thin films and exchange anisotropy," in Magnetism, vol. III, G. T. Rado and H. Suhl, Eds. New York: Academic, 1963, pp. 271-350.

[4] K. Elissa, "Title of paper if known," unpublished.

[5] R. Nicole, "Title of paper with only first word capitalized," J. Name Stand. Abbrev., in press.

[6] Y. Yorozu, M. Hirano, K. Oka, and Y. Tagawa, "Electron spectroscopy studies on magneto-optical media and plastic substrate interface,” IEEE Transl. J. Magn. Japan, vol. 2, pp. 740-741, August 1987 [Digests 9th Annual Conf. Magnetics Japan, p. 301, 1982]. 